Journal of Molecular Microbiology and Biotechnology

Albrecht, D. 53

Antelmann, H. 53

Antranikian, G. 81

Ballschmiter, M. 81

Beloqui, A. 109

Borriss, R. 14

Bowien, B. 124

Bringer-Meyer, S. 6

Chen, X.H. 14

Cramm, R. 38

Daniel, R. 25

Deppenmeier, U. 69

Ehrenreich, A. 53, 69

Evers, S. 53

Ferrer, M. 109
Fricke, W.F. 124

Frishman, D. 81

Golyshin, P.N. 109

Gordon, P.M.K. 81

Görisch, H. 6

Gottschalk, G. 5, 53

Hecker, M. 53

Hölscher, T. 6

Jaeger, K.E. 25

Klenk, H.-P. 81

Koumoutsi, A. 14

Kusian, B. 124

Liebl, W. 81

Maurer, K.-H. 53

Merfort, M. 6
Reinecke, F. 91

Ruepp, A. 81

Sahm, H. 6

Schleyer, U. 6

Scholz, R. 14

Schweder, T. 53

Sensen, C.W. 81

Stark, M. 81

Steele, H.L. 25

Steinbüchel, A. 91

Streit, W.R. 25

Timmis, K.N. 109

van Dijl, J.M. 53

Voigt, B. 53

Zibat, A. 81

\title{
Subject Index Vol. 16, No. 1-2, 2009
}

Acetic acid bacteria 69

Anaerobranca gottschalkii 81

- - amylolytic enzymes 81

Bacillaene 14

Bacillus amyloliquefaciens 14

- licheniformis 53

- subtilis 53

Bacilysin 14

Biocatalyst 25

Bioplastics 91

Biotechnologically useful enzymes 81

Biotechnology 69

Biotransformation 109

Burkholderiacea(e) 124

- genomes 124

Cell physiology 53

Cupriavidus necator H16 124

Cyanophycin 91

Cyclic lipopeptides 14
Denitrification 38

Difficidin 14

Electron transport pathways 38

Energy metabolism 38

Extracellular proteome 53

Functional screening 25

Genome 14

- organization 124

Gluconobacter 6

Glucose oxidation 6

3HB-oligomer hydrolase 91

Heterologous host 25

Hydrogen oxidation 38

5-Keto-D-gluconate 6

Lithoautotrophy 38

Macrolactin 14

Metagenome 109

Metagenomics 25

Microbial polyesters 91
Partial genome sequencing 81

PHA depolymerase 91

- synthase 91

Phasin 91

PHB 91

Polyketides 14

PQQ-dependent dehydrogenases 6

Protein engineering 109

- secretion 53

Pyrroloquinoline quinone-dependent dehydrogenases 69

Quinoproteins 6

Ralstonia eutropha 38, 91

- $\quad$ - strain H16 124

Rapid access to genes 81

Shotgun 109

Siderophore 14

Vinegar 69 